\title{
Molecules and their functions in autophagy
}

\author{
Jong-Ok Pyo, Jihoon Nah and Yong-Keun Jung ${ }^{1}$ \\ School of Biological Science/Bio-MAX Institute \\ Seoul National University \\ Seoul 151-747, Korea \\ ${ }^{1}$ Corresponding author: Tel, 82-2-880-4401; \\ Fax, 82-2-873-7524; E-mail, ykjung@snu.ac.kr \\ http://dx.doi.org/10.3858/emm.2012.44.2.029 \\ Accepted 19 January 2012 \\ Available Online 19 January 2012
}

Abbreviations: AMPK, AMP-activated protein kinase; Atg, Atg proteins; CMA, chaperone-mediated autophagy; ESCRT, endosomal sorting complex required for transport; IP3, myo-inositol-1,4,5-triphosphate; mTOR, mammalian Target of rapamycin; mTORC1, mTOR complex 1; NSF, orthologue of the N-ethylmaleimide-sensitive fusion; PAS, pre-autophagosome; $\mathrm{PE}$, phosphatidylethanolamine; $\mathrm{PI}(3) \mathrm{P}$, phosphatidylinositol 3-phosphate; PI3K, phosphatidylinositol 3-kinase; ROS, reactive oxygen species

\begin{abstract}
Autophagy is a self-degradation system of cellular components through an autophagosomal-lysosomal pathway. Over the last $15 \mathrm{yr}$, yeast genetic screens led to the identification of a number of genes involved in the autophagic pathway. Most of these autophagy genes are present in higher eukaryotes and regulate autophagy process for cell survival and homeostasis. Significant progress has recently been made to better understand the molecular mechanisms of the autophagy machinery. Especially, autophagy process, including the regulation of autophagy induction through mTOR and the nucleation and elongation in autophagosome formation through class III phosphatidylinositol 3-kinase complex and ubiquitin-like conjugation systems, became evident. While many unanswered questions remain to be answered, here, we summarize the recent process of autophagy with emphasis on molecules and their protein complexes along with advanced molecular mechanisms that regulate the autophagy machinery.
\end{abstract}

Keywords: ATG2 protein, human; ATG5 protein, human; ATG9B protein, human; ATG12 protein, human;
ATG16L1 protein, human; autophagy; class III phosphatidylinositol 3-kinases; MTOR protein, human; ULK1 protein, human

\section{Introduction}

Autophagy is an evolutionarily conserved and highly regulated lysosomal pathway that degrades macromolecules (e.g. proteins, glycogen, lipids and nucleotides) and organelles (Cuervo, 2004; Levine and Klionsky, 2004). Recent progress has demonstrated that autophagy plays an essential role in cellular development and differentiation (Levine and Klionsky, 2004) and its dysregulation is implicated in various diseases, including cancer, infectious disease, obesity, aging and neurodegenerative disorders such as Alzheimer's, Parkinson's and Huntington's diseases (Huang and Klionsky, 2007; Mizushima et al., 2008; Lee et al., 2012).

Depending on the delivery route of the cytoplasmic material to the lysosome, there are three major types of autophagy in eukaryotes; 1) chaperonemediated autophagy (CMA), 2) microautophagy and 3) macroautophagy, hereafter referred to as autophagy (Klionsky, 2005). CMA allows the direct lysosomal import of unfolded, soluble proteins which contain a particular pentapeptide motif. In microautophagy, cytoplasmic material is directly engulfed into the lysosome at the surface of the lysosome by membrane rearrangement. Autophagy involves the sequestration of cytoplasm into a double-membrane cytosolic vesicle, referred to as an autophagosome that subsequently fuses with a lysosome to form an autolysosome for the degradation by lysosomal hydrolases (Klionsky and Emr, 2000). Autophagy is the major regulated- cellular pathway for degrading long-lived proteins and is the only known pathway for degrading cytoplasmic organelles (Yang and Klionsky, 2009). Autophagy consists of several sequential steps, which are induction, autophagosome formation, autophagosomelysosome fusion and degradation. Although autophagy has been extensively studied at the cellular level for more than four decades, its molecular mechanisms have just started to be elucidated in the past few years, mainly due to the application of yeast genetics. In this review, we summarize the 
Table 1. Identification of Atg genes and their functions in mammals.

\begin{tabular}{ll}
\hline \multicolumn{1}{c}{ Autophagy-related gene (Atg) - products } \\
\hline MLmmalian Atg gene & \multicolumn{1}{c}{ Functions } \\
\hline Atg2 & Protein Kinase: Atg1-Atg13-Atg17-Atg29 complex \\
Atg3 & Atg9/Atg2-Atg18 complex \\
Atg4A,B,C,D & E2-like enzyme for Atg8s-lipidation \\
Atg5 & Cysteine protease: Atg8s-activation and delipidation \\
Beclin-1 & Atg12-Atg5 conjugate: E3-like activity for Atg8s-lipidation \\
Atg7 & Subunit of Vps34 PI3K complex \\
LC3, GATE-16, GABARAP & E1-like enzyme for Atg12-and LC3-conjugation \\
Atg9L1, L2 & Modifier: Conjugates to PE to localize to Autophagosome \\
Atg10 & Atg9 interacts Atg2-Atg18 complex: membrane-bound \\
Atg12 & E2-like enzyme for Atg12-conjugation \\
Atg13 & Modifier: Conjugates to Atg5 \\
Atg14 & mTor signaling: Atg1-Atg13-Atg17-Atg29 complex \\
Atg16L & Subunit of Vps34 PI3K complex \\
FIP200 & Complex between Atg16 and Atg12-Atg5 conjugate \\
WIPI-1,2,3,4 & Atg1-Atg13-Atg17-Atg29 complex \\
\hline
\end{tabular}

molecular mechanisms of autophagy process, especially focusing on autophagosome formation.

\section{The process of autophagy}

While autophagy has been studied in mammals since the 1950's, yeast genetics has allowed us to understand this process at a molecular level. To date, 32 genes that are involved in autophagy have been identified in mammals (Table 1) and these have been termed as autophagy-related genes (Atg) (He and Klionsky, 2009). Among these, 16 genes (Atg 1-10, 12-14, 16 and 18) are required for all types of autophagy mentioned above (Suzuki and Ohsumi, 2007; Xie and Klionsky, 2007; Longatti and Tooze, 2009). These Atg proteins function at several physiologically continuous steps in autophagy and are generally classified into six groups. (1) The ULK1 kinase complex (ULK1-mAtg13FIP200-Atg101) for the induction of autophagy, (2) Atg9 for recycling membrane, (3) class III phosphatidylinositol 3-kinase (PI3K) complex (Vps34-Beclin1Vps15-mAtg14) for vesicle nucleation, (4) phosphatidylinositol 3-phosphate[PI(3)P]-binding Atg2-Atg18 complex (WIPI1/2 in mammals), (5) Atg12-Atg5Atg16 conjugation system and (6) Atg8 conjugation system involving phosphatidylethanolamine (Atg8$\mathrm{PE}$ ) for membrane expansion (Mizushima, 2010).

\section{Regulation of autophagy induction through mTOR and ULK1 complexes}

Under stress conditions such as amino acid starvation, autophagy is strongly induced in many types of cultured cells. The effects of individual amino acids differ in their abilities to regulate autophagy. Amino acids including Leu, Tyr, Phe, GIn, Pro, His, Trp, Met and Ala suppress autophagy in ex vivo perfused liver (Mortimore and Pösö, 1987). However, such profiles depend on cell types showing their different amino acid metabolisms in tissues. The questions on how cells sense amino acid concentration and physiological significance of autophagy regulation by amino acid starvation are not fully understood yet. Accumulated reports demonstrated that amino acid signaling pathways exist, which involve activation of serine/ threonine kinase mammalian Target of rapamycin (mTOR) and the subsequent regulation of the class III PI3K. The mTOR is involved in the control of multiple cell processes in response to changes in nutrient conditions (Nobukuni et al., 2005). Especially, mTOR complex1 (mTORC1) requires Rag GTPase, Rheb and Vps34 for its activation and subsequent inhibition of autophagy in response to amino acids (Wullschleger et al., 2006; Sancak et al., 2010). Energy levels are primarily sensed by AMPactivated protein kinase (AMPK), a key factor for cellular energy homeostasis. In low energy states, AMPK is activated and the activated AMPK then inactivates mTORC1 through TSC1/TSC2 and Rheb protein (Gwinn et al., 2008). Thus, inactivation of mTORC1 is essential for the induction of autophagy and plays a central role in autophagy. In addition to amino acid signaling, hormones, growth factors and many other factors, including bcl-2 (Levine et al., 2008), reactive oxygen species (ROS) (Botti et al., 2006), calcium (Green and Wang, 2010), BNIP3 (Tracy et al., 2007), p19ARF 
(Sherr, 2006), DRAM (Crighton et al., 2007), calpain (Xia et al., 2010), TRAIL (Mills et al., 2004), FADD (Pyo et al., 2005) and myo-inositol-1,4,5triphosphate (IP3) (Sarkar and Rubinsztein, 2006), have also been reported to regulate autophagy. But, not all autophagy signals are transduced through mTOR signaling. A recent study showed that small-molecule enhancers of the cytostatic effects of rapamycin (called SMERs) induce autophagy independently of mTOR (Sarkar et al., 2007).

The essential process of autophagy is conserved from yeast to mammals. A distinct difference between yeast and mammalian autophagy is the presence of transient pre-autophagosome (PAS) in yeast. A protein complex composed of Atg1 (serine/threonine kinase), Atg13 (scaffold protein), $\operatorname{Atg} 17$, Atg29 and Atg31 is required for the formation of PAS structure and functions in the initial step of autophagosome formation in yeast. Similarly, the ULK1 kinase complex consisting of ULK1 (Atg1), mAtg13 (Atg13), FIP200 (Atg17) and Atg101 exists in mammals. Unlike in yeast, however, the ULK1 kinase complex in mammal is likely to be stably formed for autophagosome formation regardless of nutrient conditions (Ganley et al., 2009; Mercer et al., 2009; Kuma and Mizushima, 2010).

Activities of the ULK1 kinase complex are regulated by mTOR, depending on nutrient conditions.
Under growing and high-nutrient conditions, the active mTORC1 interacts with the ULK1 kinase complex (ULK1-mAtg13-FIP200-Atg101) and phosphorylates ULK1 and mAtg13, and thus inhibits the membrane targeting of the ULK1 kinase complex. During starvation condition, on the other hand, the inactivated mTORC1 dissociates from the ULK1 kinase complex and results in the ULK1 kinase complex free to phosphorylate components, such as mAtg13 and FIP200, in the ULK1 kinase complex, leading to autophagy induction (Mizushima, 2010) (Figure 1).

\section{The Class III PI3K complex in autophagosome nucleation}

Autophagosome formation process is composed of isolation membrane nucleation, elongation and completion steps. In mammals, the class III PI3K complex plays an essential role in isolation membrane nucleation during autophagy (Mariño and López-Otín, 2004), while the class I PI3K pathway is also involved in autophagy regulation through insulin signaling cascade to activate mTOR and PKB (Yang and Klionsky, 2009). The class III $\mathrm{PI} 3 \mathrm{~K}(\mathrm{Vps} 34)$ is associated with Beclin1 (Atg6) and $\mathrm{p} 150$, the homolog of Vps15 (phosphoinositide-3kinase, regulatory subunit 4 ), to form the class III $\mathrm{PI} 3 \mathrm{~K}$ core complex. As the first step of autophagosome formation, autophagosome nucleation

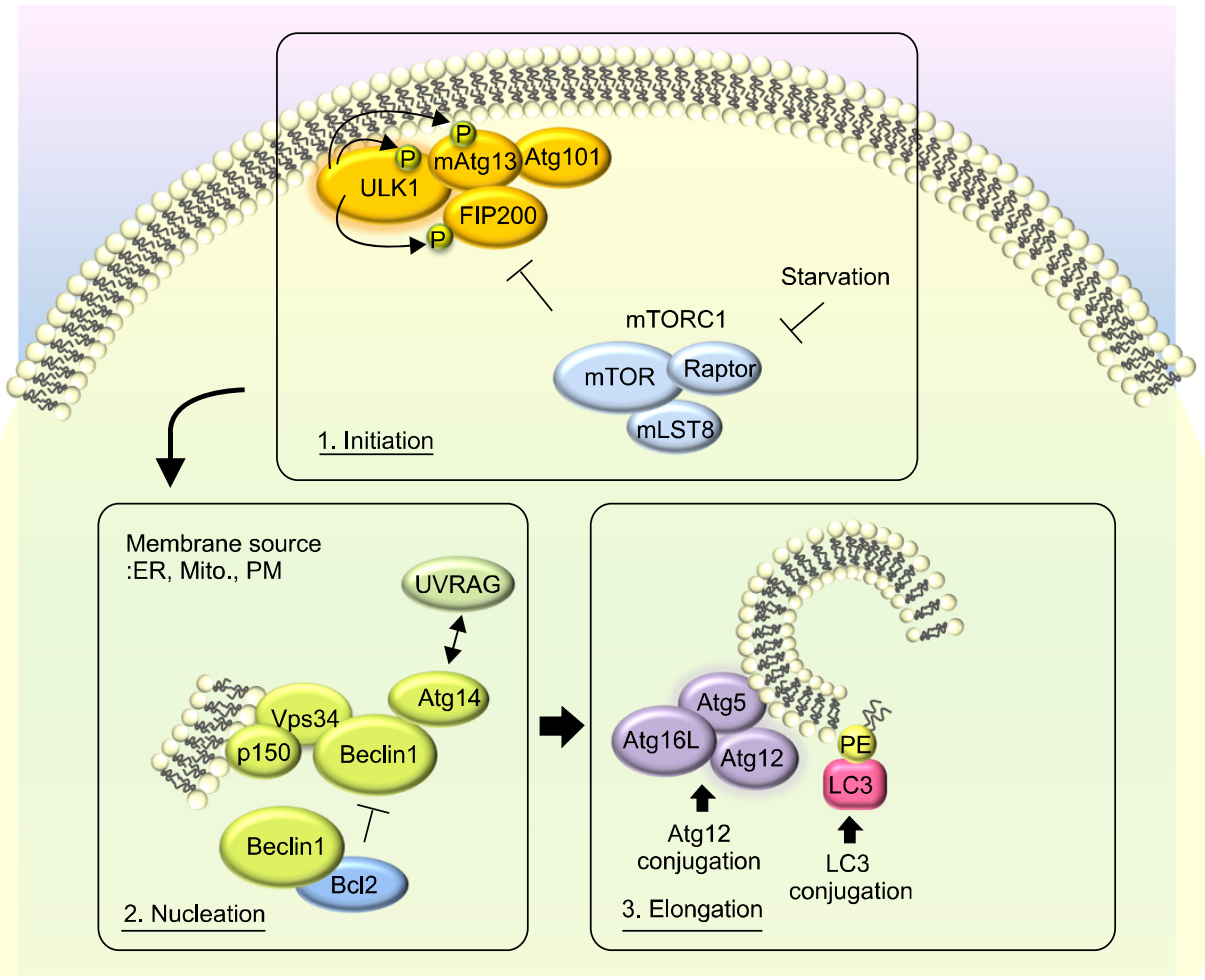

Figure 1. Molecular regulation of autophagosome formation in mammalian macroautophagy. Three major steps consisting of the initiation, nucleation and elongation in autophagosome formation are described. ER, endoplasmic reticulum; Mito, mitochondria; PM, plasma membrane; $\mathrm{PE}$, phosphatidylethanolamine. 
requires Beclin1. Mammalian Beclin1, which was identified as an interaction partner of $\mathrm{Bcl}-2$ (Liang et al., 1998), associates with the class III PI3K core complex to generate $\mathrm{PI}(3) \mathrm{P}$ (Funderburk et al., 2010). The interaction of Beclin1 with Vps34 is known to promote the catalytic activity of VPS34 and increase levels of PI(3)P, but is dispensable for the normal function of Vps34 in protein trafficking or recruitment of endocytic events (Wurmser et al., 1999; Zeng et al., 2005).

Beclin1 plays an essential role in the initiation step of autophagy and is also involved in the pathogenesis of diseases such as pathogen infection, cancer and neurodegeneration (Levine and Kroemer, 2008). Despite the proposed roles, molecular function of Beclin1 is poorly understood. Some hints on the molecular function of Beclin1 are likely to be found in its many binding partners and several studies actually provide biological significance of these interactions. Depending on the proteins recruited by Beclin1, class III PI3K complexes differentially regulate the process of autophagosome formation (Proikas-Cezanne and Codogno, 2011). Various additional components of Beclin1 complex were recently identified. (1) Atg14L (the probable mammalian homologue of yeast Atg14) exists primarily in a Beclin1-Atg14L- Vps34-Vps15 complex that is essential for the formation of autophagosome (Itakura et al., 2008; Funderburk et al., 2010). (2) UV radiation resistance-associated gene (UVRAG) is present in a Beclin1-UVRAG-Vps34-Vps15 complex. Atg14L and UVRAG are located in the Beclin1-Vps34-Vps15 complex in a mutually exclusive manner (Liang et al., 2008). (3) Activating molecule in Beclin1-regulated autophagy (AMBRA1) is a positive regulator of the Beclin1-dependent autophagy and regulates developments of the nervous system (Fimia et al., 2007). (4) Bax-interacting factor 1 (Bif1) interacts with Beclin1 through UVRAG. Bif1 positively regulates autophagy and suppresses of tumorigenesis (Takahashi et al., 2007). Other additional proteins, including PTEN-induced putative kinase 1 (PINK1), neuronal isoform of proteininteraction, specifically with TC10 (nPIST) (Yue et al., 2002), IP3 receptor (IP3R) (Vicencio et al., 2009), the pancreatitis- associated protein, vacuole membrane protein 1 (VMP1) (Ropolo et al., 2007) and high mobility group box 1 (HMGB1) (Kang et al., 2010), have also been identified as Beclin1interacting proteins.

In contrast to these positive regulators, there are negative regulators among Beclin1-interacting partners. (5) RUN domain- and cysteine-rich domaincontaining Beclin1-interacting protein (Rubicon) negatively regulates autophagosome maturation by interacting with Beclin1 contrastively to Atg14L
(Matsunaga et al., 2009). (6) Bcl2 and BclXL also bind to Beclin1 through their $\mathrm{BH} 3$ domain and inhibit autophagy by disrupting the interaction between Beclin1 and class III PI3K complex (Pattingre et al., 2005; He and Levine, 2010). Despite identification of numerous aforementioned molecules, it is not clear how class III PI3K complex regulates autophagosome nucleation. According to a recent study, one of Beclin1-interacting protein, Barkor/ Atg14(L), was suggested to directly bind to membrane composed of $\mathrm{PI}(3) \mathrm{P}$ generated by PI3KC3 (Fan et al., 2011). By binding preferentially to the curved membranes incorporated with $\mathrm{PI}(3) \mathrm{P}$, Barkor may be capable of sensing and maintains membrane curvature to initiate autophagosomal membrane formation. However, the assembly of the class III PI3K complexes and how they act with other components in the class III PI3K complex need to be further characterized.

\section{Ubiquitin-like protein conjugation systems in autophagosome expansion}

The expansion of the isolation membrane is basically the simultaneous elongation and nucleation of little cistern. It is not known yet how the Atg12-Atg5 complex recruits additional membranes, but two ubiquitin-like protein conjugation systems are involved in the expansion of autophagosome membranes (Figure 2). The first ubiquitin-conjugation

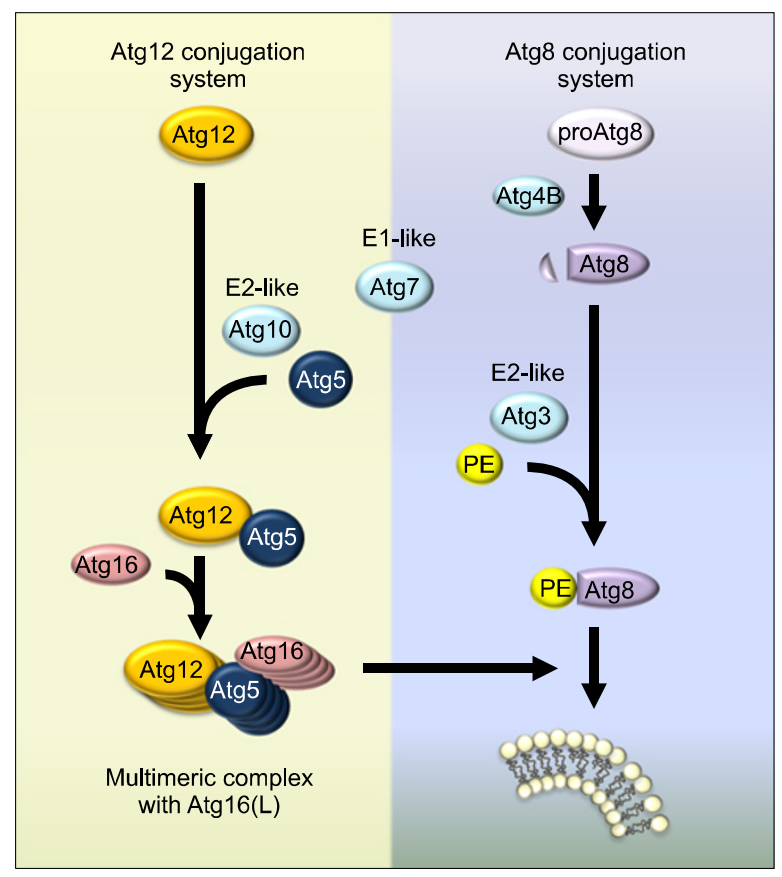

Figure 2. Ubiquitin-like protein conjugation systems in autophagy. 
system is Atg12-Atg5-Atg16L which is essential for the formation of pre-autophagosomes. Atg12 is a 186 -amino acid protein and is conjugated to Atg5 (Kuma et al., 2002). The carboxy-terminal glycine residue of $\operatorname{Atg} 12$ is activated by E1-like Atg7 through a high energy thioester bond in an ATP-dependent manner (Mizushima et al., 1998; Kim et al., 1999; Yuan et al., 1999; Tanida et al., 2001). Atg12 is then transferred to E2-like Atg10 (Shintani et al., 1999) and finally attached to lysine 149 of Atg5 via an isopeptide bond (Mizushima et al., 1998). The Atg12-Atg5 conjugate further interacts with Atg16L1 to form a $\sim 350 \mathrm{kDa}$ multimeric Atg12-Atg5-Atg16 protein complex through the homo-oligomerization of Atg16 (Mizushima et al., 1999) (Figure 2, left). Once autophagosome formation is completed, Atg proteins are released back to the cytoplasm by a yet uncharacterized mechanism.

The second ubiquitin-like protein conjugation system is the modification of LC3 (a mammalian homolog of Atg8) by the phospholipid phosphatidylethanolamine (PE) (Ichimura et al., 2000), an essential process for the formation of autophagosomes (Figure 2, right). LC3 is cleaved by cysteine protease Atg 4 and then conjugated with $P E$ by Atg7 and Atg3, a second E2-like enzyme. This lipidated LC3-II then associates with newly forming autophagosome membranes. LC3-II remains on mature autophagosomes until its fusion with lysosomes (Burman and Ktistakis, 2010). The conversion of LC3 to LC3-II is thus well-known as a marker of autophagy-induction. However, the increase of LC3-II alone is not enough to show autophagy activation because the inhibition of LC3-II degradation in the lysosome by the impaired autophagy flux can also cause its accumulation.

While the origin of autophagic vacuoles remains disputable, several hypotheses have been proposed for the source of autophagosomal membrane during autophagosome formation. The first hypothesis is "de novo" formation of autophagosome by Atg9 reservoirs (Mari et al., 2010). In the second hypothesis, various organelles such as ER (HayashiNishino et al., 2009), mitochondria (Hailey et al., 2010) and plasma membrane (Ravikumar et al., 2010) are used as an origin for the formation of the phagophore (Figure 1). Recently, cup-shaped structures called omegasome, a discrete region of the $E R$, was identified as a platform for autophagosome formation (Tooze and Yoshimori, 2010). The Atg5 complex, LC3 and ULK1 were shown to be recruited into the omegasome after starvation, and Atg5- and LC3-positive membranes seem to emerge from the omegasome. It was also observed that omegasomes form in close proximity to the Vps34- containing vesicles which may synthesize the $\mathrm{PI}(3) \mathrm{P}$. This hypothesis is also supported by a notion of a physical association between the ER and early autophagic membranes (Hayashi-Nishino et al., 2009).

\section{Vesicle completion and lysosomal degradation}

Autophagosome then fuses with lysosomes/vacuoles, which is an essential process for completion of the autophagy pathway. Sequestration of cytoplasm into a double-membrane cytosolic vesicle is followed by the fusion of the vesicle with a late endosome or lysosome to form an autophagolysosome (or autolysosome). Then, inner membrane of the autophagosome and autophagosome-containing cytoplasmderived materials are degraded by lysosomal/vacuolar hydrolases inside the autophagosome. The molecular mechanisms underlying the transport and fusion of autophagosomes are just beginning to be understood, and through active investigations, several major events involved in the process have recently been clarified.

In yeast, the fusion of autophagosomes with the vacuole requires SNARE machinery and proteins such as the vacuolar syntaxin homologue Vam3 (Darsow et al., 1997), the SNAP-25 homologue Vam7 (Sato et al., 1998), the Rab family GTP. binding protein Ypt7 (Mayer et al., 1997) or the orthologue of the $\mathrm{N}$-ethylmaleimide-sensitive fusion (NSF) protein, Sec18 (Ishihara et al., 2001). In mammalian cells, autophagosome maturation is a prior step for the fusion between autophagosomes and lysosomes. Like in yeast, the activity of monomeric GTPases such as Rab22 and Rab24 is required for autophagosome maturation (Petiot et al., 2000), and mammalian orthologues of SNARE protein family members and the NSF protein may also be involved in the maturation of autophagic vesicles.

Recent studies have identified new regulators of autophagosome maturation and degradation, including UVRAG (Liang et al., 2008), Rubicon (Matsunaga et al., 2009), presenillin-1 (Lee et al., 2010), valosin-containing protein (VCP) (Tresse et al., 2010) and syntaxin-5 SNARE complex proteins (Renna et al., 2011). In addition, the endosomal sorting complex required for transport (ESCRT), which had originally been identified in the recognition and sorting of ubiquitin-modified cargo proteins into multivesicular bodies (MVBs) (Rothman and Wieland, 1996), was recently found to play a role in autophagosome-lysosome fusion (Rusten et al., 2007). Furthermore, ESCRT machinery was shown to be required for phagophore closure (Raiborg and Stenmark, 2009), autophagosome fu- 
sion (Lee et al., 2007) and lysosome biogenesis (Raiborg et al., 2008). The degradation products, including macromolecules, are then exported to the cytosol for re-utilization by the cell. This process is poorly understood.

\section{Conclusion}

In the past decade there has been an extraordinary advance in our understanding of the molecular signaling involved in mammalian autophagy. Actually, genetic screens in yeast have identified numerous Atg genes that regulate autophagy process. In spite of those outcomes, many outstanding questions remain to be elucidated, including the origin of the membrane source for autophagosome formation, mechanism of phagophore expansion and autophagosome formation and regulation of ubiquitin-like conjugation system in autophagy process (Chen and Klionsky, 2011). Recently, two interesting approaches have been employed to identify new autophagy regulators: small molecules screening (Zhang et al., 2007; Farkas et al., 2009) and studies on structural information of Atg proteins. From our knowledge, autophagy is a major contributor to maintain cellular homeostasis and metabolism. It is also involved in the pathogenesis of human diseases. Thus, continued studies to identify key molecules regulating autophagy and a better understanding for the process at molecular level are required to be further proceeded.

\section{Acknowledgements}

The author thanks Yoo SM and Jung SM for preparation of the figures in this manuscript. Dr. Pyo JO and Nah J were partly supported by the Brain Korea-21 program. This work was supported by the grants of Global Research Laboratory program [K21004000002-11A0500-00210] and BAERI program (2011-0006314, Jung $Y K)$ and by the grant from Basic Research for Woman Scientists (Pyo JO) of the Korea Research Foundation.

\section{References}

Botti J, Djavaheri-Mergny $\mathrm{M}$, Pilatte $\mathrm{Y}$, Codogno $\mathrm{P}$. Autophagy signaling and the cogwheels of cancer. Autophagy 2006;2:67-73

Burman C, Ktistakis NT. Autophagosome formation in mammalian cells. Semin Immunopathol 2010;32:397-413

Chen Y, Klionsky DJ. The regulation of autophagyunanswered questions. J Cell Sci 2011;124:161-70

Crighton D, Wilkinson S, Ryan KM. DRAM links autophagy to p53 and programmed cell death. Autophagy 2007;3:72-4
Cuervo AM. Autophagy: In sickness and in health. Trends Cell Biol 2004;14:70-7

Darsow T, Rieder SE, Emr SD. A multispecificity syntaxin homologue, Vam3p, essential for autophagic and biosynthetic protein transport to the vacuole. J Cell Biol 1997; 138:517-29

Fan W, Nassiri A, Zhong Q. Autophagosome targeting and membrane curvature sensing by Barkor/Atg14(L). Proc Natl Acad Sci USA 2011;108:7769-74

Farkas T, Hoyer-Hansen M, Jäättelä M. Identification of novel autophagy regulators by a luciferase-based assay for the kinetics of autophagic flux. Autophagy 2009;5:1018-25

Fimia GM, Stoykova A, Romagnoli A, Giunta L, Di Bartolomeo S, Nardacci R, Corazzari M, Fuoco C, Ucar A, Schwartz P, Gruss P, Piacentini M, Chowdhury K, Cecconi F. Ambra1 regulates autophagy and development of the nervous system. Nature 2007;447:1121-5

Funderburk SF, Wang QJ, Yue Z. The Beclin 1-VPS34 complex-at the crossroads of autophagy and beyond. Trends Cell Biol 2010;20:355-62

Ganley IG, du Lam H, Wang J, Ding X, Chen S, Jiang X. ULK1.ATG13.FIP200 complex mediates mTOR signaling and is essential for autophagy. J Biol Chem 2009;284: 12297-305

Green DR, Wang R. Calcium and energy: making the cake and eating it too? Cell 2010;142:200-2

Gwinn DM, Shackelford DB, Egan DF, Mihaylova MM, Mery A, Vasquez DS, Turk BE, Shaw RJ. AMPK phosphorylation of raptor mediates a metabolic checkpoint. Mol Cell 2008;30: 214-26

Hailey DW, Rambold AS, Satpute-Krishnan P, Mitra K, Sougrat R, Kim PK, Lippincott-Schwartz J. Mitochondria supply membranes for autophagosome biogenesis during starvation. Cell 2010;141:656-67

Hayashi-Nishino M, Fujita N, Noda T, Yamaguchi A, Yoshimori T, Yamamoto A. A subdomain of the endoplasmic reticulum forms a cradle for autophagosome formation. Nat Cell Biol 2009;11:1433-7

He C, Klionsky DJ. Regulation mechanisms and signaling pathways of autophagy. Annu Rev Genet 2009;43:67-93

$\mathrm{He}$ C, Levine B. The Beclin 1 interactome. Curr Opin Cell Biol 2010;22:140-9

Huang J, Klionsky DJ. Autophagy and human disease. Cell Cycle 2007;6:1837-49

Ishihara N, Hamasaki M, Yokota S, Suzuki K, Kamada Y, Kihara A. Autophagosome requires specific early Sec proteins for its formation and NSF/SNARE for vacuolar fusion. Mol Biol Cell 2001;12:3690-702

Ichimura Y, Kirisako T, Takao T, Satomi Y, Shimonishi Y, Ishihara N. A ubiquitin-like system mediates protein lipidation. Nature 2000;408:488-92

Itakura E, Kishi C, Inoue K, Mizushima N. Beclin 1 forms two distinct phosphatidylinositol 3-kinase complexes with mammalian Atg14 and UVRAG. Mol Biol Cell 2008;19: 5360-72 
Kang R, Livesey KM, Zeh HJ, Loze MT, Tang D. HMGB1: a novel Beclin 1-binding protein active in autophagy. Autophagy 2010;6:1209-11

Kim J, Dalton VM, Eggerton KP, Scott SV, Klionsky DJ. Apg7p/Cvt2p is required for the Cvt, macroautophagy and peroxisome degradation pathway. Mol Biol Cell 1999;10: 1337-51

Klionsky DJ. The molecular machinery of autophagy: unanswered questions. J Cell Sci 2005;118:7-18

Klionsky DJ, Emr SD. Autophagy as a regulated pathway of cellular degradation. Science 2000;290:1717-21

Kuma A, Mizushima N. Physiological role of autophagy as an intracellular recycling system: with an emphasis on nutrient metabolism. Semin Cell Dev Biol 2010;7:683-90

Kuma A, Mizuchima N, Ishihara N, Ohsumi, Y. Formation of the approximately $350 \mathrm{kDa}$ Apg12-Apg5-Apg16 multimeric complex, mediated by Apg 16 oligomerization, is essential for autophagy in yeast. J Biol Chem 2002;277:18619-25

Lee H, Noh JY, Oh Y, Kim Y, Chang JW, Chung CW, Lee ST, Kim M, Ryu H, Jung YK. IRE1 plays an essential role in ER stress-mediated aggregation of mutant huntingtin via the inhibition of autophagy flux. Hum Mol Genet 2012;21:101-14

Lee JA, Beigneux A, Ahmad ST, Young SG, Gao FB. ESCRT-III dysfunction causes autophagosome accumulation and neurodegeneration. Curr Biol 2007;17:1561-7

Lee JH, Yu WH, Kumar A, Lee S, Mohan PS, Peterhoff CM, Wolfe DM, Martinez-Vicente M, Massey AC, Sovak G, Uchiyama Y, Westaway D, Cuervo AM, Nixon RA. Lysosomal proteolysis and autophagy require presenilin 1 and are disrupted by Alzheimer-related PS1 mutations. Cell 2010; 141:1146-58

Levine B, Klionsky DJ. Development by self-digestion: Molecular mechanisms and biological functions of autophagy. Dev Cell 2004;6:463-77

Levine B, Kroemer G. Autophagy in the pathogenesis of disease. Cell 2008;132:27-42

Levine B, Sinha S, Kroemer G. Bcl-2 family members: dual regulators of apoptosis and autophagy. Autophagy 2008;4: 600-6

Liang C, Lee JS, Inn KS, Gack MU, Li Q, Roverts EA, Vergne I, Deretic V, Feng P, Akazawa C. Beclin 1-binding UVRAG targets the class $\mathrm{C}$ Vps complex to coordinate autophagosome maturation and endocyticc trafficking. Nat Cell Biol 2008;10:776-87

Liang XH, Kleeman LK, Jiang HH, Gordon G, Goldman JE, Berry G, Herman B, Levine B. Protection against fatal Sindbis virus encephalitis by Beclin, a novel Bcl-2-interacting protein. J Virol 1998;72:8586-96

Longatti A, Tooze SA. Vesicular trafficking and autophagosome formation. Cell Death Differ 2009;16:956-65

Mari M, Griffith J, Rieter E, Krishnappa L, Klionsky DJ, Reggiori F. An Atg9-containing compartment that functions in the early steps of autophagosome biogenesis. J Cell Biol 2010;190:1005-22

Mariño G, López-Otín C. Autophagy: molecular mechanisms, physiological functions and relevance in human pathology. Cell Mol Life Sci 2004;61:1439-54

Matsunaga K, Saitoh T, Tabata K, Omori H, Satoh T, Kurotori N, Maejima I, Shirahama-Noda K, Ichimura T, Isobe T. Two Beclin 1-binding proteins, Atg14L and Rubicon, reciprocally regulate autophagy at different stages. Nat Cell Biol 2009;11: 385-96

Mayer A, Wickner W. Docking of yeast vacuoles is catalyzed by the Ras-like GTPase Ypt7p after symmetric priming by Sec18p (NSF). J Cell Biol 1997;136:307-17

Mercer CA, Kaliappan A, Dennis PB. A novel, human Atg13 binding protein, Atg101, interacts with ULK1 and is essential for macroautophagy. Autophagy 2009;5:649-62

Mills KR, Reginato M, Debnath J, Queenan B, Brugge JS. Tumor necrosis factor-related apoptosis-inducing ligand (TRAIL) is required for induction of autophagy during lumen formation in vitro. Proc Natl Acad Sci USA 2004;101: 3438-43

Mizushima N, Noda T, Yoshimori T, Tanaka Y, Ishii T, George MD, Klionsky DJ, Ohsumi M, Ohsumi Y. A protein conjugation system essential for autophagy. Nature 1998;395:395-8

Mizushima N, Noda T, Ohsumi Y. Apg16p is required for the function of the Apg12p-Apg5p conjugate in the yeast autophagy pathway. EMBO 1999;18:3888-96

Mizushima N, Levine B, Cuervo AM, Klionsky DJ. Autophagy fights disease through cellular self digestion. Nature 2008; 451:1069-75

Mizushima, N. The role of the Atg1/ULK1 complex in autophagy regulation. Curr Opin Cell Biol 2010;22:132-9

Mortimore GE, Pösö AR. Intracellular protein catabolism and its control during nutrient deprivation and supply. Annu Rev Nutr 1987;7:539-64

Nobukuni T, Joaquin M, Roccio M, Dann SG, Kim SY, Gulati $P$, Byfield MP, Backer JM, Natt F, Bos JL, Zwartkruis FJ, Thomas G. Amino acids mediate mTOR/raptor signaling through activation of class 3 phosphatidylinositol $3 \mathrm{OH}$ kinase. Proc Natl Acad Sci USA 2005;102:14238-43

Pattingre S, Tassa A, Qu X, Garuti R, Liang XH, Mizushima N, Packer M, Schneider MD, Levine B. Bcl-2 antiapoptotic proteins inhibit Beclin 1-dependent autophagy. Cell 2005; 122:927-36

Petiot A, Ogier-Denis E, Blommaart EF, Meijer AJ, Codogno $P$. Distinct classes of phosphatidylinositol 3'-kinases are involved in signaling pathways that control macroautophagy in HT-29 cells. J Biol Chem 2000;275:992-8

Proikas-Cezanne T, Codogno P. Beclin 1 or not Beclin 1. Autophagy 2011;7:671-2

Pyo JO, Jang MH, Kwon YK, Lee HJ, Jun JI, Woo HN, Cho $\mathrm{DH}$, Choi B, Lee H, Kim JH, Mizushima N, Oshumi Y, Jung YK. Essential roles of Atg5 and FADD in autophagic cell death: dissection of autophagic cell death into vacuole formation and cell death. J Biol Chem 2005;280:20722-9

Raiborg C, Malerod L, Pedersen NM, Stenmark H. Differential functions of Hrs and ESCRT proteins in endocytic membrane trafficking. Exp Cell Res 2008;314:801-13 
Raiborg C, Stenmark H. The ESCRT machinery in endosomal sorting of ubiquitylated membrane proteins. Nature 2009;458:445-52

Ravikumar B, Moreau K, Jahreiss L, Puri C, Rubinsztein DC. Plasma membrane contributes to the formation of preautophagosomal structures. Nat Cell Biol 2010;12:747-57

Renna M, Schaffner C, Winslow AR, Menzies FM, Peden AA, Floto RA, Rubinsztein DC. Autophagic substrate clearance requires activity of the syntaxin-5 SNARE complex. J Cell Sci 2011;124:469-82

Ropolo A, Grasso D, Pardo R, Sacchetti ML, Archange C, Lo Re A, Seux M, Nowak J, Gonzalez CD, lovanna JL, Vaccaro MI. The pancreatitis-induced vacuole membrane protein 1 triggers autophagy in mammalian cells. J Biol Chem 2007;282:37124-33

Rothman JE, Wieland FT. Protein sorting by transport vesicles. Science 1996;272:227-34

Rusten TE, Stenmark H. How do ESCRT proteins control autophagy? J Cell Sci 2009;122:2179-83

Rusten TE, Vaccari T, Lindmo K, Rodahl LM, Nezis IP, Sem-Jacobsen C, Wendler F, Vincent JP, Brech A, Bilder D. ESCRTs and Fab1 regulate distinct steps of autophagy. Curr Biol 2007;17:1817-25

Sancak Y, Bar-Peled L, Zoncu R, Markhard AL, Nada S, Sabatini DM. Ragulator-Rag complex targets mTORC1 to the lysosomal surface and is necessary for its activation by amino acids. Cell 2010;141:290-303

Sarkar S, Perlstein EO, Imarisio S, Pineau S, Cordenier A, Maglathlin RL, Webster JA, Lewis TA, O'Kane CJ, Schreiber SL, Rubinsztein DC. Small molecules enhance autophagy and reduce toxicity in Huntington's disease models. Nat Chem Biol 2007;3:331-8

Sarkar S, Rubinsztein DC. Inositol and IP3 levels regulate autophagy: biology and therapeutic speculations. Autophagy 2006;2:132-4

Sato TK, Darsow T, Emr SD. Vam7p, a SNAP- 25-like molecule, and Vam3p, a syntaxin homolog, function together in yeast vacuolar protein trafficking. Mol Cell Biol 1998;18: 5308-19

Sherr CJ. Autophagy by ARF: a short story. Mol Cell 2006;22: 436-7

Shintani T, Mizushima N, Ogawa Y, Matsuura A, Noda T, Ohsumi Y. Apg10p, a novel protein-conjugating enzyme essential for autophagy in yeast. EMBO J 1999;18:5234-41

Suzuki K, Ohsumi Y. Molecular machinery of autophagosome formation in yeast, Saccharomyces cerevisiae. FEBS Lett 2007;581:2156-61

Takahashi Y, Coppola D, Matsushita N, Cualing H, Sun M, Sato Y, Liang C, Jung JU, Cheng JQ, Mule JJ et al. Bif-1 interacts with Beclin 1 through UVRAG and regulates autophagy and tumorigenesis. Nat Cell Biol 2007;9:1142-51
Tanida I, Tanida-Miyake E, Ueno T, Kominami E. The human homolog of Saccharomyces cerevisiae Apg7p is a proteinactivating enzyme for multiple substrates including human Apg12p, GATE-16, GABARAP, and MAP-LC3. J Biol Chem 2001;276:1701-6

Tooze SA, Yoshimori T. The origin of the autophagosomal membrane. Nat Cell Biol 2010;12:831-5

Tracy K, Dibling BC, Spike BT, Knabb JR, Schumacker P, Macleod KF. BNIP3 is an RB/E2F target gene required for hypoxia-induced autophagy. Mol Cell Biol 2007;27:6229-42

Tresse E, Salomons FA, Vesa J, Bott LC, Kimonis V, Yao TP, Dantuma NP, Taylor JP. VCP/p97 is essential for maturation of ubiquitin-containing autophagosomes and this function is impaired by mutations that cause IBMPFD. Autophagy 2010;6:217-27

Vicencio JM, Ortiz C, Criollo A, Jones AW, Kepp O, Galluzzi L, Joza N, Vitale I, Morselli E, Tailler M, Castedo M, Maiuri MC, Molgó J, Szabadkai G, Lavandero S, Kroemer G. The inositol 1,4,5-trisphosphate receptor regulates autophagy through its interaction with Beclin 1. Cell Death Differ 2009; 16:1006-17

Wullschleger S, Loewith R, Hall MN. TOR signaling in growth and metabolism. Cell 2006;124:471-84

Wurmser AE, Gary JD, Emr SD. Phosphoinositide 3-kinases and their FYVE domain-containing effectors as regulators of vacuolar/lysosomal membrane trafficking pathways. J Biol Chem 1999;274:9129-32

Yang Z, Klionsky DJ. An overview of the molecular mechanism of autophagy. Curr Top Microbiol Immunol 2009;335:1-32

Yuan W, Stromhaug PE, Dunn WA Jr. Glucose-induced microautophagy of peroxysomes in Pichia pastoris requires a unique E1-like protein. Mol Biol Cell 1999;10:1353-66

Yue Z, Horton A, Bravin M, DeJager PL, Selimi F, Heintz N. A novel protein complex linking the delta 2 glutamate receptor and autophagy: implications for neurodegeneration in lurcher mice. Neuron 2002;35:921-33

Xia HG, Zhang L, Chen G, Zhang T, Liu J, Jin M, Ma X, Ma D, Yuan J. Control of basal autophagy by calpain1 mediated cleavage of ATG5. Autophagy 2010;6:61-6

Xie Z, Klionsky DJ. Autophagosome formation: core machinery and adaptations. Nat Cell Biol 2007;9:1102-9

Zeng $\mathrm{X}$, Overmeyer JH, Maltese WA. Functional specificity of the mammalian Beclin-Vps34 PI 3-kinase complex in macroautophagy versus endocytosis and lysosomal enzyme trafficking. J Cell Sci 2006;119:259-70

Zhang L, Yu J, Pan H, Hu P, Hao Y, Cai W, Zhu H, Yu AD, Xie $X, M a D$. Small molecule regulators of autophagy identified by an image-based high-throughput screen. Proc Natl Acad Sci USA 2007;104:19023-8 